\title{
The impact of sirolimus on hepatitis $C$ recurrence after liver transplantation
}

\author{
Sonal Asthana MD MRCS(Edinburgh) ${ }^{1}$, Christian Toso MD PhD ${ }^{1}$, Glenda Meeberg MSc${ }^{1}$, David L Bigam MD FRCSC ${ }^{1}$, \\ Andrew Mason MBBS MRCPI ${ }^{2}$, AM James Shapiro MD PhD ${ }^{1}$, Norman M Kneteman MD FRCSC ${ }^{1}$
}

\begin{abstract}
S Asthana, C Toso, G Meeberg, et al. The impact of sirolimus on hepatitis $\mathrm{C}$ recurrence after liver transplantation. Can J Gastroenterol 2011;25(1):28-34.
\end{abstract}

BACKGROUND: While some immunosuppression strategies may accelerate hepatitis $\mathrm{C}$ virus ( $\mathrm{HCV}$ ) recurrence after liver transplantation (LT), the impact of sirolimus (SRL) is not known.

OBJECTIVE: To assess the risk of biopsy-proven HCV recurrence and patient survival using known and suspected risk factors for HCV recurrence as covariates.

METHODS: A retrospective analysis of 141 consecutive patients, including 88 who received de novo SRL therapy, who had undergone a first LT for HCV cirrhosis was conducted. Known and suspected risk factor covariates including transplant era, donor and recipient age, Model for End-stage Liver Disease score, cold ischemia time, immunosuppressive drugs and steroid treatment rejection rates were used in the assessment.

RESULTS: Overall, $72.3 \%$ of the cohort developed biopsy-proven $\mathrm{HCV}$ recurrence. The incidence of HCV recurrence was not significantly different for patients treated with SRL (75\% versus $69.8 \%$; $\mathrm{P}=0.5$ ). There was no difference found for time to recurrence, nor did mean activity or fibrosis scores differ at the time of initial recurrence. However, on follow-up using serial biopsies in patients with recurrence, the mean activity and fibrosis scores were significantly lower in the SRL group. Donor age and acute rejection episodes were the only factors affecting the HCV recurrence rate (expB 1.02 [95\% CI 1.01 to 1.03$]$ ); $\mathrm{P}=0.03$; and expB 2.8 [95\% CI 1.8 to 4.3]; $\mathrm{P}<0.01$ ], respectively). SRL treatment did not alter patient survival rates. Among patients treated with SRL-based immunosuppression, higher drug area under the curve levels were associated with a trend to lower disease activity and fibrosis at diagnosis; however, higher SRL levels were associated with shorter recurrence-free survival $(\mathrm{P}=0.038)$.

CONCLUSION: Results of the present analysis suggest that de novo SRL-based immunosuppression can be safely used in patients undergoing LT for HCV-associated liver disease; however, SRL-based immunosuppression did not significantly affect the timing or severity of post-transplant HCV recurrence. HCV recurrence in SRL-treated patients had lower progressive activity and fibrosis levels on serial biopsy.

Key Words: Hepatitis C; Immunosuppression; Liver transplantation; Recurrence; Sirolimus

epatitis $\mathrm{C}$ virus (HCV)-associated cirrhosis is the most
common indication for liver transplantation (LT) in the western world (1). Post-transplant recurrence of HCV is universal and is associated with higher viral load than pretransplant viral load, more rapid progression to liver allograft cirrhosis, and higher allograft failure and mortality rates (2-7).

There are several donor, immunological and recipient factors that promote progression to allograft failure following HCV recurrence in liver allograft recipients (8). The degree of

\section{Les effets du sirolimus sur la récurrence d'hépatite $\mathrm{C}$ après une greffe du foie}

HISTORIQUE : Certaines stratégies d'immunosuppression peuvent accélérer la récurrence du virus d'hépatite $\mathrm{C}(\mathrm{VHC})$ après une greffe du foie (GF), mais on ne connaît pas les effets du sirolimus (SRL).

OBJECTIF : Évaluer le risque de récurrence de VHC démontrée par biopsie et la survie des patients au moyen des covariables des facteurs de risque connus et présumés de récurrence du VHC.

MÉTHODOLOGIE : Les chercheurs ont procédé à une analyse rétrospective de 141 patients consécutifs, y compris 88 qui avaient reçu pour la première fois une thérapie au SRL et qui avaient subi une première GF en raison d'une cirrhose à VHC. Pour procéder à l'évaluation, ils ont utilisé les covariables des facteurs de risque connus et présumés, y compris l'époque de la greffe, l'âge du donneur et du receveur, l'indice du modèle de maladie du foie en phase terminale, la période d'ischémie froide ainsi que les taux de rejet des immunosuppresseurs et de la corticothérapie.

RÉSULTATS : Dans l'ensemble, 72,3\% des membres de la cohorte ont acquis une récurrence de $\mathrm{VHC}$ démontrée par biopsie. L'incidence de récurrence de VHC n'était pas significativement différente pour les patients traités au SRL (75 \% par rapport à 69,8\%; P=0,5). Les chercheurs n'ont constaté ni différence de délai avant la récurrence ni différence d'activité moyenne ou d'indices de fibrose au moment de la récurrence initiale. Cependant, au suivi effectué par biopsies sérielles chez les patients ayant une récurrence, l'activité moyenne et les indices de fibrose étaient considérablement plus faibles dans le groupe prenant du SRL. L'âge du donneur et les épisodes de rejet aigus étaient les seuls facteurs touchant le taux de récurrence de VHC $(\operatorname{expB} 1,02$ [95 \% IC 1,01 à 1,03]); P=0,03; et expB 2,8 [95 \% IC 1,8 à 4,3]; P<0,01], respectivement). Le traitement au SRL ne modifiait pas le taux de survie des patients. Chez les patients traités par immunosuppression au SRL, une plus grande surface de médicaments sous la courbe s'associait à une tendance vers une plus faible activité de la maladie et de la fibrose au diagnostic. Cependant, des taux de SRL plus élevés s'associaient à une survie plus courte sans récurrence $(\mathrm{P}=0,038)$.

CONCLUSION : D'après les résultats de la présente analyse, une nouvelle immunosuppression au SRL peut être utilisée en toute sécurité chez les patients qui subissent une GF en raison d'une maladie hépatique liée au VHC. Cependant, l'immunosuppression par le SRL ne changeait pas le moment ou la gravité de la récurrence de $\mathrm{VHC}$ de manière significative après la greffe. La récurrence de VHC chez les patients traités au SRL présentait une activité progressive et un taux de fibrose plus faibles à la biopsie sérielle.

immunosuppression (IS), especially high-dose steroid use and $\mathrm{T}$ cell-depleting antibodies, adversely affects the post-transplant course of $\mathrm{HCV}$.

While the impact of sirolimus (SRL) therapy on HCV recurrence following LT has not been well studied, several of its properties have the potential to alter the rate of HCV recurrence. SRL has a marked antiproliferative and antifibrotic effect, which may retard HCV progression to cirrhosis. In addition, SRL may have some antiviral effect, of which two cases

${ }^{1}$ Department of Surgery, Section of Hepatobiliary, Pancreatic and Transplant Surgery, ${ }^{2}$ Department of Medicine, Division of Gastroenterology,

University of Alberta, Edmonton, Alberta

Correspondence: Dr Norman M Kneteman, Department of Surgery, University of Alberta, 2D4.41 Walter Mackenzie Centre, Edmonton,

Alberta T6G 2B7. Telephone 780-407-6168, fax 780-407-7374, e-mail norm.kneteman@albertahealthservices.ca

Received for publication July 13, 2010. Accepted July 30, 2010 
involving spontaneous clearance of HCV following a switch from tacrolimus-based IS to SRL therapy have been reported (9).

The present study was conducted to assess the impact of de novo SRL treatment on the timing and severity of posttransplant HCV recurrence.

\section{METHODS}

\section{Patients}

All adult patients who underwent initial LT for HCV between January 1998 and December 2006 at a single centre were included in the present analysis. To improve comparability in groups of patients and provide a minimum of 12 months of follow-up, data were extracted from the time when SRL-based IS was first used in the Department of Surgery, University of Alberta (Edmonton, Alberta) (January 1998) up to December 2006. Patients selected for SRL-based IS during this time period included the following: all patients with hepatocellular carcinoma (HCC, $n=39$ ), patients with significant pre- or post-transplant renal dysfunction $(n=10)$, and a consecutive pilot series of patients between June 2000 and October 2001 $(n=39)$.

Only patients who were initiated on SRL-based IS within one month of transplant and remained on it for at least 12 months were included in the SRL group. This group was compared with a group of patients who received calcineurin inhibitor (CNI)-based IS. Seventeen patients, who were either started on SRL more than one month after LT or had received fewer than 12 months of continuous treatment, were excluded from analysis. All patients in the latter one-half of the study period (after 2002) received induction therapy with anti-CD25 monoclonal antibody (daclizumab or basiliximab). The transplant eras (1998 to 2002, and 2002 to 2006) were defined based on changes in the IS practice of the centre to study the effect of anti-CD25 antibody treatment in the present cohort. Patients on SRL also received low-dose CNIs, except for patients with HCC, who were converted to SRL monotherapy in 12 months time. Thirty patients with HCC (75\%) were tapered off CNIs within the first 12 months. None of the patients received routine maintenance steroids; patients on CNIs without SRL also received mycophenolate mofetil up to $2 \mathrm{~g}$ per day as tolerated. While therapeutic tacrolimus levels for the CNI group were maintained between $8 \mathrm{ng} / \mathrm{mL}$ and $10 \mathrm{ng} / \mathrm{mL}$ (600 $\mathrm{ng} / \mathrm{mL}$ to $800 \mathrm{ng} / \mathrm{mL}$ in the cyclosporine group), patients receiving SRL and CNI were maintained on SRL levels of between $8 \mathrm{ng} / \mathrm{mL}$ and $12 \mathrm{ng} / \mathrm{mL}$, and tacrolimus levels of $5 \mathrm{ng} / \mathrm{mL}$ to $8 \mathrm{ng} / \mathrm{mL}$, or C2 levels of $400 \mathrm{ng} / \mathrm{mL}$ to $600 \mathrm{ng} / \mathrm{mL}$ (Figure $1 \mathrm{~A}$ and $1 \mathrm{~B})$.

Data regarding donor and recipient age, recipient sex, Model for End-stage Liver Disease (MELD) score, pre-LT diabetes on oral hypoglycemics or insulin, recipient ethnicity, cold ischemia time, biopsy-proven rejection and requirement for pulse steroids were collected prospectively in an electronic patient record (OTTR, Hickman Kenyon Systems, USA). Outcome data of two separate eras - 1998 to 2002, and 2003 to 2006 - were analyzed to account for changes in IS practice and clinical management over time.

HCV recurrence, proven by abnormal liver function tests in the absence of rejection and confirmed on liver biopsy, was the primary end point of the present study. The necroinflammatory state of $\mathrm{HCV}$ recurrence was reported according to

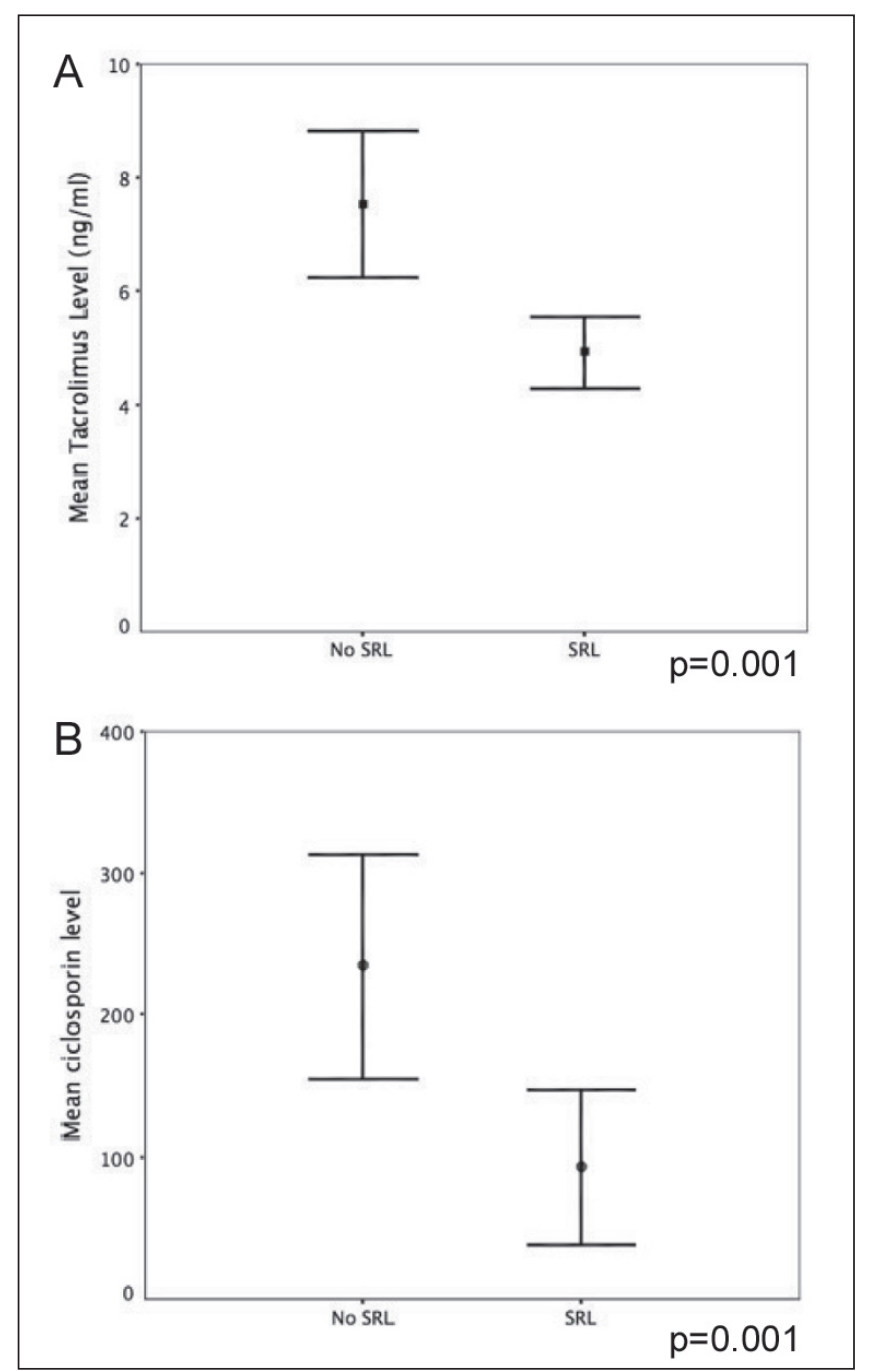

Figure 1) A Comparison of cumulative tacrolimus exposure over 12 months between groups. B Comparison of cumulative cyclosporine exposure over 12 months between groups. Error bars represent standard error of the mean. No SRL Calcineurin inhibitor-only group; SRL Sirolimus group

the Metavir classification as follows: 0 , no fibrosis; 1 , minimal fibrosis without any septa; 2, portal fibrosis with rare septa; 3, numerous septa with bridging fibrosis without cirrhosis; and 4, cirrhosis (10). Secondary end points included biopsy-proven acute rejection, time to $\mathrm{HCV}$ recurrence, and graft and patient survival. All biopsy slides were reviewed by a liver pathologist to ascertain disease stage and activity.

Data regarding the most recent biopsy available for patients who developed HCV recurrence were collected, and the mean change in activity of the disease over the duration of the follow-up period was compared between IS groups.

A stepwise multivariate Cox regression analysis was used to identify factors independently associated with recurrence-free survival. Recurrence-free survival was computed from the day of surgery to the day of biopsy-proven recurrence or, in patients without recurrence, to the most recent follow-up visit. Follow-up of patients who died without evidence of $\mathrm{HCV}$ recurrence was censored at the time of death. 
TABLE 1

Patient and donor characteristics

\begin{tabular}{|c|c|c|c|}
\hline & \multicolumn{2}{|c|}{ Immunosuppression } & \multirow[b]{2}{*}{$\mathbf{P}$} \\
\hline & $\begin{array}{c}\text { SRL based } \\
(n=88)\end{array}$ & $\begin{array}{l}\text { CNI based } \\
(n=53)\end{array}$ & \\
\hline Recipient age, years, mean (range) & $51.3(42-74)$ & $50.8(28-63)$ & 0.7 \\
\hline Male sex, n (\%) & $71(80.6)$ & $40(75.4)$ & 0.52 \\
\hline Diabetes mellitus, $\mathrm{n}$ & 22 & 12 & 0.8 \\
\hline Non-Caucasian, n (\%) & $4(4.5)$ & $10(18.8)$ & 0.008 \\
\hline Pretransplant dialysis, $\mathrm{n}$ & 10 & 0 & 0.01 \\
\hline Hepatocellular carcinoma, $n$ & 39 & 1 & $<0.001$ \\
\hline MELD score at $L T$, mean \pm SD & $17.8 \pm 9.5$ & $13.8 \pm 7.5$ & 0.02 \\
\hline Body mass index, $\mathrm{kg} / \mathrm{m}^{2}($ mean $\pm \mathrm{SD})$ & $26.6 \pm 5.2$ & $24.0 \pm 4.4$ & 0.01 \\
\hline Donor age, years, mean (range) & $42.5(14-74)$ & $42(16-69)$ & 0.6 \\
\hline Cold ischemia time, min (mean \pm SD) & $385 \pm 209$ & $404 \pm 170$ & 0.3 \\
\hline \multicolumn{4}{|l|}{ Transplant era, $n$} \\
\hline 1998 to 2002 & 40 & 28 & 0.48 \\
\hline 2003 to 2006 & 48 & 25 & 0.48 \\
\hline $\begin{array}{l}\text { Cumulative } 12 \text {-month tacrolimus } \\
\text { exposure, } \mathrm{ng} / \mathrm{mL} \text { (mean } \pm \mathrm{SD} \text { ) }\end{array}$ & $4.9 \pm 2.9$ & $7.5 \pm 3.9$ & $<0.001$ \\
\hline $\begin{array}{l}\text { Cumulative } 12 \text {-month cyclosporine } \\
\text { exposure, } \mathrm{ng} / \mathrm{mL} \text { (mean } \pm \mathrm{SD} \text { ) }\end{array}$ & $92 \pm 102$ & $221 \pm 181.5$ & 0.01 \\
\hline
\end{tabular}

CNI Calcineurin inhibitor; LT Liver transplantation; MELD Model for End-stage Liver Disease; SRL Sirolimus

Further analysis was performed to determine whether the level of exposure to SRL affected the time to recurrence, or the activity or severity of recurrent disease as calculated by the Metavir score. For this purpose, blood levels of SRL were analyzed at postoperative days 3, 7, 14 and 30, and months 3, 6, 9 and 12 in all patients who reached these time points within the study period. The period investigated started from postoperative day 3 and ended at the time of HCV recurrence diagnosis or at the end of the first year after LT. The area under the curve (AUC) of the SRL blood concentrations versus the time course (drug-AUC) was calculated during the study period using the trapezoidal rule. Given that follow-up duration was not equal for all patients, 'drug exposure' was calculated by dividing drugAUCs by the time of exposure to the drugs, as previously described (11).

Further statistical analyses were performed using $\chi^{2}$ tests and $t$ tests for categorical and continuous variables, respectively. Nonparametric data were analysed using the Kruskal-Wallis test. All statistical analysis was performed using SPSS version 15.0 software (SPSS Inc, USA). Data are presented as mean \pm SD unless specified otherwise. A standard alpha of 0.05 indicated statistical significance. The present study was approved by the institutional health research ethics board panel.

\section{Demographics}

\section{RESULTS}

A total of 141 patients who underwent LT for HCV-related cirrhosis during the study period met the inclusion criteria. Most patients were men ( $\mathrm{n}=111$ [78.7\%]); $90.5 \%$ of the cohort was Caucasian. The median age of the cohort was 51.2 years (range 36.4 to 74.3 years), and the median follow-up period was 54 months (range one to 122 months). Eighty-eight (62.4\%) of these patients received SRL-based IS, 112 received tacrolimus and 33 received cyclosporine. Due to rejection, 14 patients were required to be switched from cyclosporine to tacrolimus during follow-up.
TABLE 2

Hepatitis C recurrence

\begin{tabular}{lccc}
\hline \multicolumn{3}{c}{ Immunosuppression } \\
\hline & $\begin{array}{c}\text { SRL based } \\
(\mathbf{n = 8 8})\end{array}$ & $\begin{array}{c}\text { CNI based } \\
(\mathbf{n = 5 3 )}\end{array}$ & $\mathbf{P}$ \\
\hline Biopsy-proven recurrence, n (\%) & $65(73.8)$ & $37(69.8)$ & 0.2 \\
Mean time to recurrence, months (range) & $6.1(1-122)$ & $6.3(1-110)$ & 0.3 \\
Activity, mean \pm SD & $1.3 \pm 0.5$ & $1.4 \pm 0.6$ & 0.2 \\
Fibrosis, mean \pm SD & $0.6 \pm 0.8$ & $0.85 \pm 0.8$ & 0.1 \\
\hline
\end{tabular}

All variables were not significantly different between groups. CNI Calcineurin inhibitor; SRL Sirolimus

Within the SRL group, 76 patients additionally received tacrolimus, four received cyclosporine $\mathrm{C} 2$ and eight received SRL exclusively after LT. An additional 30 patients with HCC were tapered off CNIs within the first year following LT.

The demographic details of the patient subgroups are summarized in Table 1. Patients with pre-existing renal failure and those with HCC preferentially received SRL. Patients on SRL had a higher mean calculated MELD score $(17.8 \pm 9.5$ versus $13.8 \pm 7.5 ; \mathrm{P}=0.02)$ and a higher body mass index $(\mathrm{BMI})$. The cold ischemia times, donor age and distribution through the transplant eras were comparable between groups (Table 1). The trough levels of tacrolimus and cyclosporine in the CNI and SRL groups were $7.5 \pm 3.9 \mathrm{ng} / \mathrm{mL}$ versus $4.9 \pm 2.9 \mathrm{ng} / \mathrm{mL}$, and $221 \pm 181.5 \mathrm{ng} / \mathrm{mL}$ versus $92 \pm 102 \mathrm{ng} / \mathrm{mL}$, respectively (Figure 1).

\section{Rejection episodes}

Fifty-eight patients developed at least one episode of acute cellular rejection (ACR) during the study period. The SRL group demonstrated a trend to a higher incidence of biopsy-proven ACR (45.4\% versus $33.9 \%$ ), as well as multiple ACR episodes $(17.3 \%$ versus $11.1 \%)$. The mean rejection activity index between the groups was comparable $(4 \pm 1.1$ versus $4.1 \pm 1.3 ; \mathrm{P}=0.8)$. These differences failed to achieve statistical significance. One patient on SRL developed steroid-resistant rejection. More patients on CNI-based IS received pulse-steroid treatment; however, this difference did not reach statistical significance $(\mathrm{P}=0.06)$.

\section{$\mathrm{HCV}$ recurrence}

A total of 102 patients (72.3\%) developed biopsy-proven HCV recurrence at similar rates regardless of the type of IS (SRL $73.8 \%$ versus $\mathrm{CNI} 69.8 \%$; $\mathrm{P}$ value nonsignificant). There was no statistically significant difference between the time to recurrence, mean activity or fibrosis score (Table 2).

Follow-up biopsy data were available for 92 patients who experienced HCV recurrence, with a median biopsy interval between the first and most recent biopsies of 16.6 months (interquartile range one to 28.2 months). There was a significant reduction in the mean fibrosis score in the SRL group (mean fibrosis score of $0.6 \pm 0.85$ rising to $1.7 \pm 0.8$ in the $\mathrm{CNI}$ group; $1.5 \pm 0.6$ decreasing to $0.98 \pm 0.6$ in the SRL group; $\mathrm{P}=0.002$ ), while the change in the mean activity trended toward being significantly higher in the CNI group (mean activity score $1.3 \pm 0.54$ versus $1.54 \pm 0.7$ in the CNI group; $1.5 \pm 0.6$ versus $1.25 \pm 0.6$ in the SRL group; $\mathrm{P}=0.056$ ) (Figure 2).

Twenty-nine patients (20.6\%) were initiated on anti-HCV treatment, of whom 20 completed at least 48 weeks of treatment. Interestingly, four of the five patients who achieved a sustained virological response (SVR) belonged to the SRL group. 


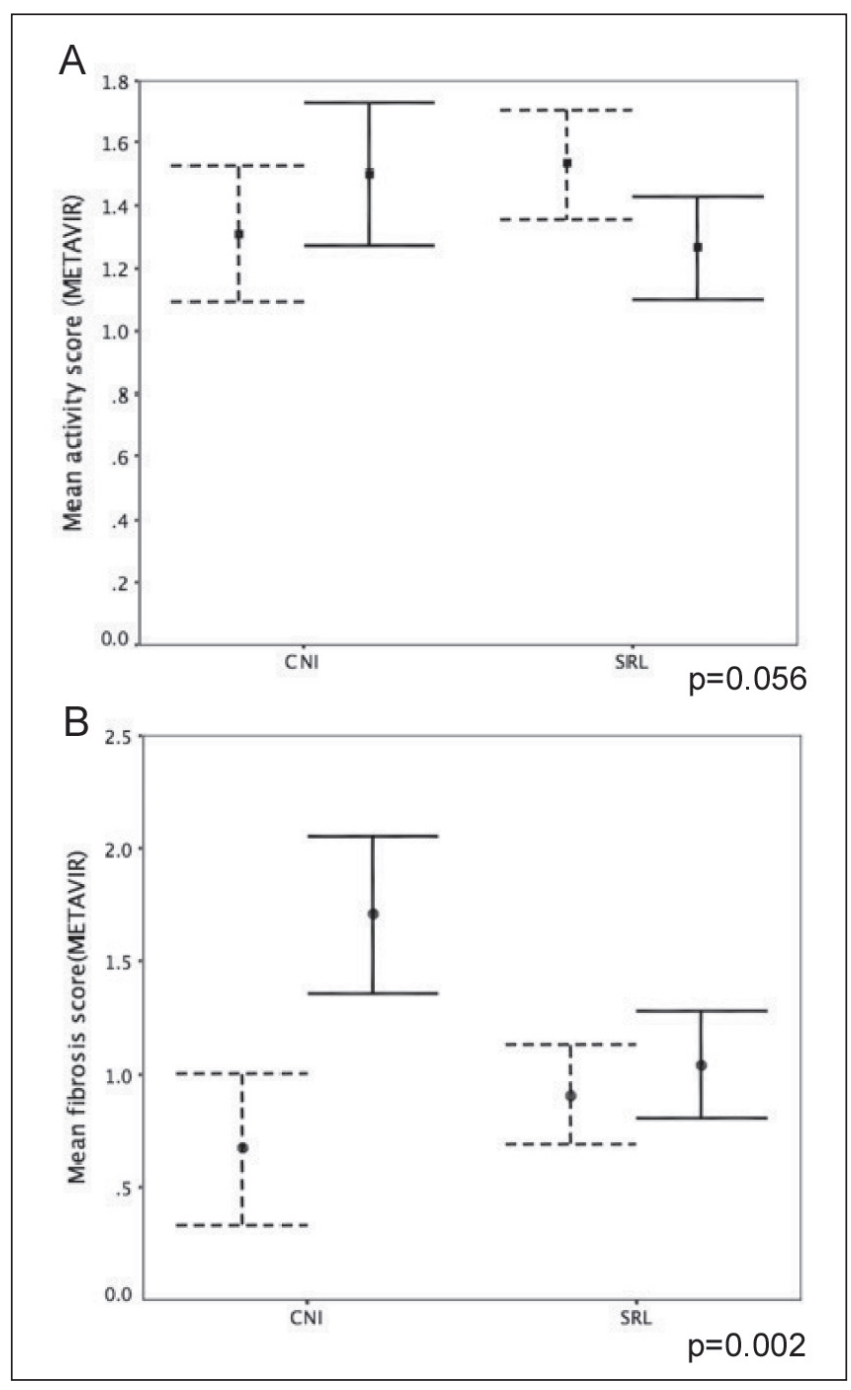

Figure 2) The progression of disease activity in patients with hepatitis $C$ virus recurrence. Dotted bars represent the mean activity and fibrosis at the first biopsy, while the solid lines represent the mean values at the most recent biopsy. Error bars represent standard error of the mean. P values compare the degree of change between immunosuppression groups. A Change in mean disease activity (Metavir) over the follow-up period compared according to immunosuppression group. B Change in mean fibrosis score (Metavir) over follow-up compared according to immunosuppression group. CNI Calcineurin inhibitor group; SRL Sirolimus group

On multivariate analysis of various donor and recipient factors potentially affecting recurrent $\mathrm{HCV}$ disease, advancing donor age and ACR episodes (expB 1.02 [95\% CI 1.01 to 1.03]; $\mathrm{P}=0.03$; and $\operatorname{expB} 2.8$ [95\% CI 1.8 to 4.3]; $\mathrm{P}<0.01$ ]) (Table 3) were the only factors found to be associated with shorter recurrence-free survival. The type of IS (SRL based versus CNI based), BMI, MELD score, pretransplant dialysis, transplant era, cold ischemia time, recipient sex and age, race, diabetes mellitus and the use of pulse steroids did not significantly impact HCV recurrence. A multivariate analysis of factors affecting patient survival was also performed, with a low BMI being the only factor that appeared to be significant (expB 0.9 [95\% CI 0.85 to 0.99]; $\mathrm{P}=0.04$ ) (Table 3). There was no
TABLE 3

Multivariate analysis (Cox regression) of factors affecting time to hepatitis $C$ virus recurrence and survival

\begin{tabular}{|c|c|c|}
\hline Recurrence & $\operatorname{expB}(95 \% \mathrm{Cl})$ & $\mathbf{P}$ \\
\hline Donor age & 1.02 (1.01-1.03) & 0.03 \\
\hline Acute rejection & $2.8(1.8-4.3)$ & $<0.01$ \\
\hline MELD score at transplant & $1.003(0.9-1.02)$ & 0.8 \\
\hline Pulse steroids & $0.9(0.5-1.9)$ & 0.9 \\
\hline Age at transplant & $1.03(0.99-1.07)$ & 0.1 \\
\hline Cold ischemia time & $0.9(0.99-1.001)$ & 0.4 \\
\hline Body mass index & $0.9(0.9-1.004)$ & 0.08 \\
\hline Recipient sex & $0.9(0.9-2.7)$ & 0.4 \\
\hline Race & $0.5(0.2-1.1)$ & 0.1 \\
\hline Transplant era & $0.9(0.6-1.5)$ & 0.8 \\
\hline Diabetes mellitus & $0.9(0.5-1.4)$ & 0.6 \\
\hline \multicolumn{3}{|l|}{ Survival } \\
\hline Body mass index & $0.9(0.85-0.99)$ & 0.04 \\
\hline Donor age & 1.01 (0.99-1.03) & 0.3 \\
\hline Acute rejection & $1.6(0.6-3.8)$ & 0.3 \\
\hline MELD score at transplant & $1.007(0.9-1.04)$ & 0.7 \\
\hline Pulse steroids & $1.6(0.6-4.7)$ & 0.4 \\
\hline Age at transplant & $1.04(0.9-1.1)$ & 0.2 \\
\hline Cold ischemia time & $1(0.99-1.002)$ & 0.9 \\
\hline Recipient sex & $0.8(0.3-2)$ & 0.6 \\
\hline Race & $1.2(0.3-5.3)$ & 0.8 \\
\hline Transplant era & $1.4(0.6-3.1)$ & 0.4 \\
\hline Diabetes mellitus & $0.9(0.4-2.03)$ & 0.7 \\
\hline
\end{tabular}

MELD Model for End-stage Liver Disease

difference in overall survival between the two groups (median survival not reached in the SRL group versus 95.3 months for CNI group; $\mathrm{P}=0.8$ ). Fourteen patients died due to liver failure secondary to recurrent HCV. Eight of these deaths were patients in the SRL group (42\% of all deaths in the cohort), while six deaths occurred in patients who were receiving CNI-based IS (25\% of the mortality in this cohort) $(\mathrm{P}=0.6)$ (Figures 3 and 4$)$.

Because patients on SRL-based IS were also treated with several other agents, including CNIs for maintenance IS, the effect of overall SRL exposure on the time to HCV recurrence, and on the degree of inflammation and fibrosis at diagnosis was estimated. The SRL exposure was analyzed over the first year or until the time of HCV recurrence. Because patients experiencing recurrence are commonly managed with a decrease in IS, potential bias may exist in analyzing the drug-AUC levels for patients with early recurrence who, as a result, may have lower IS levels at later time points compared with patients with delayed or no recurrence. Hence, drug exposure over the first three months was considered separately. Patients with higher SRL levels had a modest decrease in inflammation and fibrosis scores at diagnosis; this, however, failed to reach statistical significance (mean activity score $1.3 \pm 0.5$ versus $1.4 \pm 0.6$ $[\mathrm{P}=0.6]$; mean fibrosis score $0.6 \pm 0.8$ versus $0.85 \pm 0.8[\mathrm{P}=0.2]$ ). However, high SRL levels within the first three months were associated with a shorter time to HCV recurrence (Spearman's rho $=-0.4 ; \mathrm{P}<0.001$ for SRL exposure at three months; Spearman's rho $=-0.2 ; \mathrm{P}=0.038$ for overall $\mathrm{SRL}$ exposure) (Figure 5). 


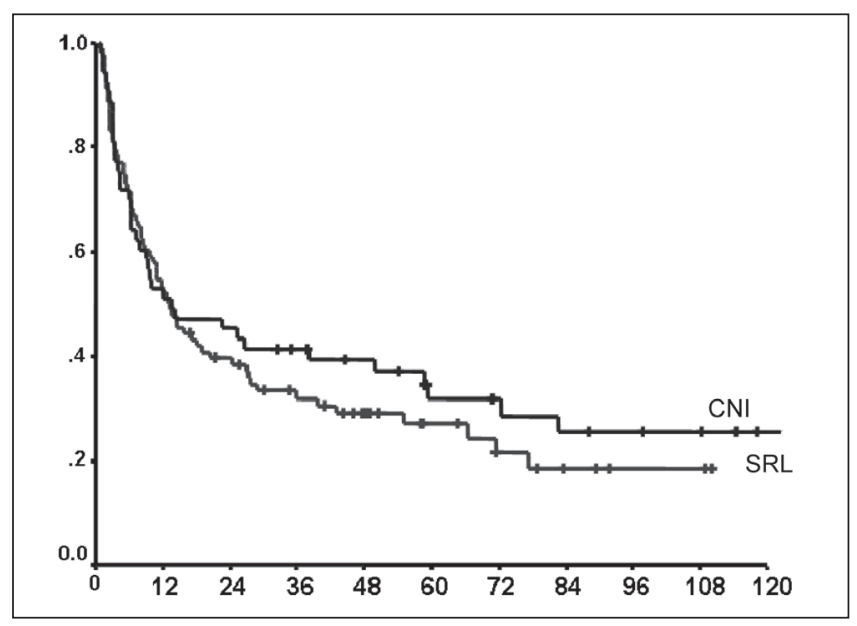

Figure 3) Comparison of recurrence-free survival according to immunosuppression (IS) $(P=0.45)$. CNI Calcineurin inhibitorbased IS group; SRL Sirolimus-based IS group

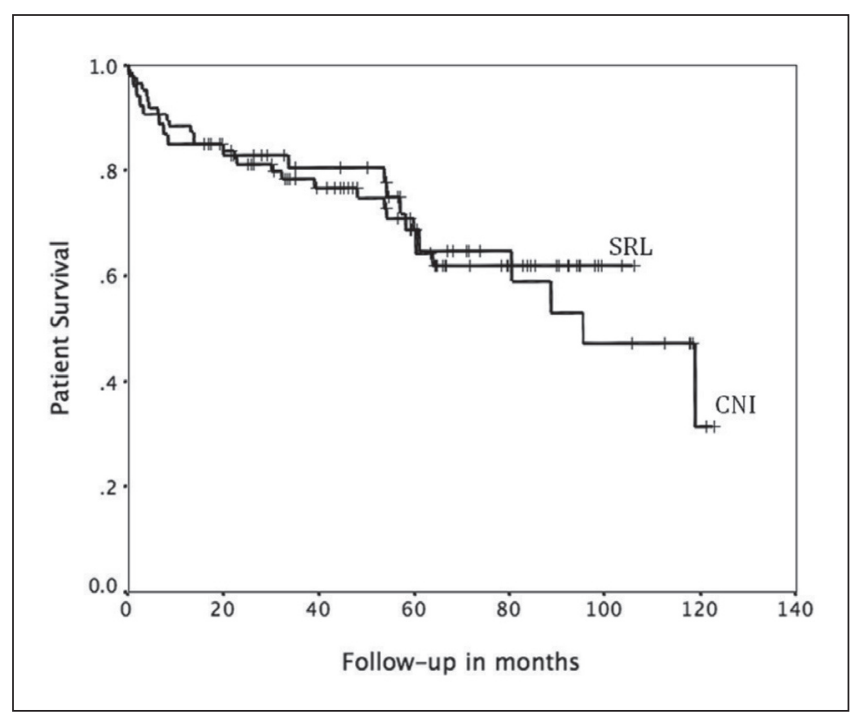

Figure 4) Kaplan-Meier plots comparing patient survival according to immunosuppression (IS). CNI Calcineurin inhibitor-based IS group; SRL Sirolimus-based IS group. $P=0.5$

\section{DISCUSSION}

Graft and patient survival following LT have improved for all indications except HCV-related cirrhosis, for which they continue to be $10 \%$ to $15 \%$ lower than non-HCV controls (12). HCV reinfection usually occurs immediately after LT, with a rapid increase in HCV RNA peaking at one to three months. Acute lobular hepatitis develops in $60 \%$ to $80 \%$ of patients at a median of four to six months, and cirrhosis in $20 \%$ by five years $(6,7)$. While recurrent HCV is universal, progression to cirrhosis is affected by several donor and patient variables including high levels of pretransplant viremia (age, steatosis and ischemic/preservation injury), HIV/cytomegalovirus coinfection, higher levels of IS (such as pulse steroids or T cell-depleting antibody use including both OKT3 or thymoglobulin), abrupt modifications of immune status and post-LT diabetes $(7,13)$.

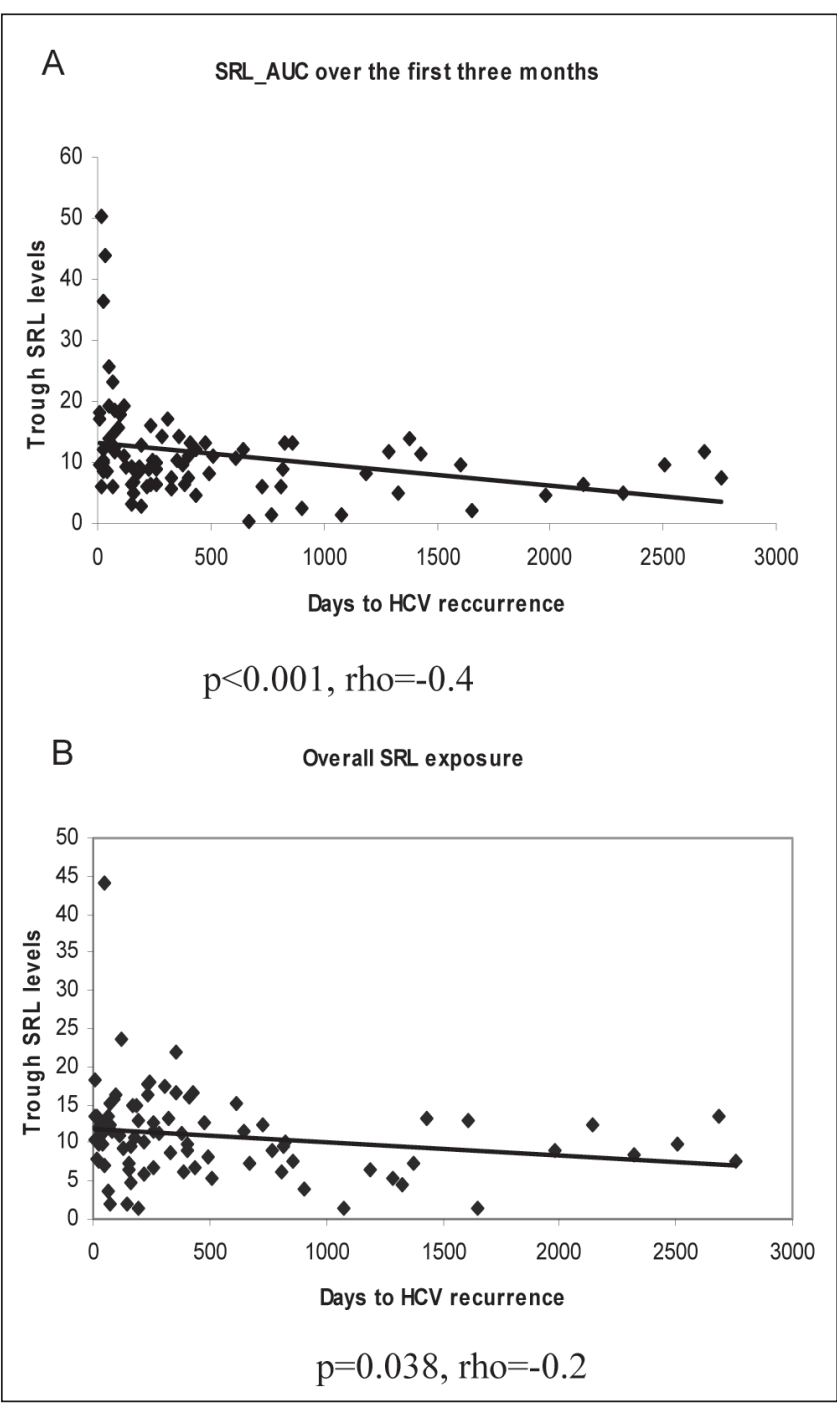

Figure 5) Scatter plots showing the effect of cumulative three-month (A) and overall (B) sirolimus (SRL) exposure on hepatitis $C$ virus (HCV) recurrence. AUC Area under the curve

Data regarding the specific effect of the different IS agents on $\mathrm{HCV}$ replication and/or progression of recurrent hepatitis $\mathrm{C}$ is controversial (14). Cyclosporine has been found to have an in vitro antiviral effect on HCV replicons (15-17), and preliminary clinical data suggest that patients on cyclosporine (when compared with tacrolimus) may experience superior SVR rates after treatment with pegylated interferon and ribavirin (15). This in vivo difference has not been well established $(18,19)$, and no literature exists on the effect of SRL on SVR rates postLT. An international survey (20) found no consensus regarding the optimal IS strategies in LT for HCV. Our experience with this group of patients suggests that although relatively few patients completed HCV therapy post-LT, four of the five patients with SVR were on SRL therapy.

SRL has potent antifungal, anti-inflammatory, antiproliferative and IS effects, but there are no reports of an antiviral effect, nor of the potential antifibrotic effects of this agent (21). Our group has previously reported on acceptable toxicity profiles with de novo SRL use in patients with $\operatorname{HCC}(22,23)$ and on evidence for a beneficial impact on outcomes of 
patients undergoing LT for HCC (24). The effect of SRL on HCV recurrence has not been well studied. A case report (9) documented the spontaneous disappearance of post-transplant serum HCV RNA in two patients who underwent LT for HCV cirrhosis and developed diabetes and renal dysfunction, and were subsequently switched to SRL therapy.

There was a nonsignificant increase in the rate of ACR episodes in the SRL group; however, more patients in the CNI group received pulse-steroid therapy. This was probably because ACR episodes in patients on combination treatment with SRL and CNI were usually treated by increasing the CNI dose. In the present study, more than $70 \%$ of patients experienced biopsy-proven HCV recurrence after 12 months. The mean time to clinically apparent recurrence in the SRL group was 6.1 months compared with 6.3 months in the CNI group - a difference that was not statistically significant. In contrast to previous reports, we did not document any cases of spontaneous HCV RNA clearance in this particular cohort (9).

SRL has been reported to have potent antifibrotic properties in rat models of liver cirrhosis, with significant inhibitory effects on procollagen-alpha 1 and transforming growth factorbeta 1 (25). Of interest, we found no difference in inflammatory activity or fibrosis index between the two groups at diagnosis in the current study. On follow-up biopsies, patients on SRL with HCV recurrence showed a significant reduction in mean fibrosis score over time and a reduced mean activity on serial biopsy. This finding is of interest despite the potential bias of sampling variation in serial biopsies.

Paradoxically, however, high-dose exposure to SRL seems to hasten recurrence within the first year, suggesting that, at higher drug levels, the immunosuppressive effect of SRL may eclipse any protective effect on the graft. There is some recent in vitro evidence (26) that higher SRL levels may markedly decrease the growth inhibition in a hepatoma cell line, which supports the possibility of a dose effect on the overall response.

On multivariate analysis, donor age and the occurrence of ACR episodes were the only factors affecting HCV recurrence. More patients in the $\mathrm{CNI}$ group required steroid boluses than the combined SRL/CNI group, in which ACR was usually managed by increasing the CNI level. While the link between $\mathrm{ACR}$ and recurrent $\mathrm{HCV}$ infection may reflect the higher levels of IS used to treat ACR with increased dosing of agents that enhance HCV replication, we did not demonstrate that the use of pulsed corticosteroid therapy affected outcome in the present study. It is also notable that patients with recurrent $\mathrm{HCV}$ infection also recruit an alloimmune response in the liver. Indeed, a review of all biopsies in patients with HCV infection in our unit revealed that recurrent HCV infection has been reported as ACR in a proportion of patients instead of recurrent $\mathrm{HCV}$ infection with features of rejection (C Hunter, A Mason, personal communication).

While lower recipient BMI was found to significantly adversely affect survival, the present study was not constructed or powered to evaluate this outcome. This finding is concordant with other studies $(27,28)$ reporting worse transplant outcomes in underweight patients.

Notably, the mean MELD score was higher in the SRL group, reflecting a higher incidence of renal dysfunction in this subgroup; however, on multivariate analysis, the MELD score did not affect outcome. The unadjusted recurrence-free survival rate was slightly higher in the CNI group; this, however, did not affect survival (Figures 2 and 3 ). Also, a trend for a better aggregate long-term survival rate was observed in the SRL group despite having a population with more renal dysfunction and HCC.

The present study had limitations inherent with retrospective analysis. HCV RNA blood level data were not available for all patients and, thus, were not included in the analysis. All patients were treated with a combination of IS agents, and the effect of individual drugs was difficult to assess due to the multiplicity of IS regimens together with the changes of drugs over time. Therefore, we estimated the drug exposure among patients on SRL-based IS by calculating the drug-AUC over the time taken to develop recurrence. Most patients are maintained on relatively high levels of IS in the first three months, which are then tapered gradually; therefore, SRL levels are substantially reduced in patients experiencing early recurrent disease. Accordingly, the drug-AUC was calculated over a shorter period of time. To address the potential bias of lower SRL levels among patients with early HCV recurrence; SRL exposure over the first three months post-transplant was computed in addition to the total SRL exposure until the time of recurrence. Higher SRL exposure at three months was associated with earlier HCV recurrence; however, the clinical significance of this finding remains unclear. HCV recurrence appears to be relatively rapid in patients with high overall levels of IS, but individual drug levels were not shown to impact the speed or the severity of disease recurrence in the present study.

We did not use protocol biopsies for the diagnosis of recurrent HCV disease, instead preferring to use clinically apparent $\mathrm{HCV}$ recurrence, which is more relevant to clinical management. This approach is consistent with previous studies, and little such data exist in literature. A recent meta-analysis on IS in HCV (14) identified only one study in which data on histological HCV disease progression based on protocol liver biopsies were available (29).

\section{CONCLUSION}

SRL can safely be used in patients undergoing LT for HCVrelated liver disease. In the present study, SRL did not significantly alter the incidence, timing or severity of $\mathrm{HCV}$ recurrence compared with CNIs alone; the use of this drug appeared to be safe in the HCV-positive recipient population. SRL-based IS is associated with lower progressive mean HCV activity and fibrosis levels on follow-up than CNIs in patients with documented HCV recurrence. ACR episodes, possibly reflecting recurrent $\mathrm{HCV}$ or increased levels of IS, and advancing donor age were the only independent predictive factors shown to adversely affect the timing of HCV recurrence.

FUNDING SOURCES: SA is supported by the Alberta Heritage Foundation for Medical Research (AHFMR), CT was supported by the Swiss National Science Foundation and the AHFMR. AMJS was supported by an AHFMR Senior Clinical Scholarship. NMK was supported by a Canadian Institutes of Health research (CIHR)/Wyeth Research Chair in Transplantation, and was a Senior Scholar of the AHFMR.

DISCLOSURE: Presented at the American Transplant Congress, Toronto, Ontario, May 31 to June 4, 2008. 


\section{REFERENCES}

1. Wong JB, McQuillan GM, McHutchison JG, Poynard T. Estimating future hepatitis $\mathrm{C}$ morbidity, mortality, and costs in the United States. Am J Public Health 2000;90:1562-9.

2. Feray C, Samuel D, Thiers V, et al. Reinfection of liver graft by hepatitis $\mathrm{C}$ virus after liver transplantation. J Clin Invest 1992;89:1361-5.

3. Wright TL, Donegan E, Hsu HH, et al. Recurrent and acquired hepatitis $\mathrm{C}$ viral infection in liver transplant recipients. Gastroenterology 1992;103:317-22.

4. Feray C, Gigou M, Samuel D, et al. The course of hepatitis C virus infection after liver transplantation. Hepatology 1994;20:1137-43.

5. Gane EJ, Naoumov NV, Qian KP, et al. A longitudinal analysis of hepatitis $\mathrm{C}$ virus replication following liver transplantation. Gastroenterology 1996;110:167-77.

6. Pelletier SJ, Iezzoni JC, Crabtree TD, Hahn YS, Sawyer RG, Pruett TL. Prediction of liver allograft fibrosis after transplantation for hepatitis $\mathrm{C}$ virus: Persistent elevation of serum transaminase levels versus necroinflammatory activity. Liver Transpl 2000;6:44-53.

7. Berenguer M, Ferrell L, Watson J, et al. HCV-related fibrosis progression following liver transplantation: Increase in recent years. J Hepatol 2000;32:673-84.

8. Wiesner RH, Sorrell M, Villamil F. Report of the first International Liver Transplantation Society expert panel consensus conference on liver transplantation and hepatitis C. Liver Transpl 2003;9(Suppl):1-9.

9. Samonakis DN, Cholongitas E, Triantos CK, et al. Sustained, spontaneous disappearance of serum HCV-RNA under immunosuppression after liver transplantation for $\mathrm{HCV}$ cirrhosis. J Hepatol 2005;43:1091-3.

10. Bedossa P, Poynard T. An algorithm for the grading of activity in chronic hepatitis C. The METAVIR Cooperative Study Group. Hepatology 1996;24:289-93.

11. Vivarelli M, Cucchetti A, La Barba G, et al. Liver transplantation for hepatocellular carcinoma under calcineurin inhibitors: Reassessment of risk factors for tumor recurrence. Ann Surg 2008;248:857-62.

12. Thuluvath PJ, Krok KL, Segev DL, Yoo HY. Trends in post-liver transplant survival in patients with hepatitis C between 1991 and 2001 in the United States. Liver Transpl 2007;13:719-24.

13. Berenguer M, Aguilera V, Prieto M, et al. Significant improvement in the outcome of HCV-infected transplant recipients by avoiding rapid steroid tapering and potent induction immunosuppression. J Hepatol 2006;44:717-22.

14. Berenguer M, Royuela A, Zamora J. Immunosuppression with calcineurin inhibitors with respect to the outcome of $\mathrm{HCV}$ recurrence after liver transplantation: Results of a meta-analysis. Liver Transpl 2007;13:21-9.

15. Firpi RJ, Zhu H, Morelli G, Abdelmalek MF, et al. Cyclosporine suppresses hepatitis $\mathrm{C}$ virus in vitro and increases the chance of a sustained virological response after liver transplantation. Liver Transpl 2006;12:51-7.

16. Watashi K, Hijikata M, Hosaka M, Yamagi M, Shimotohno K. Cyclosporin A suppresses replication of hepatitis $\mathrm{C}$ virus genome in cultured hepatocytes. Hepatology 2003;38:1282-8.

17. Nakagawa M, Sakamoto N, Tanabe Y, et al. Suppression of hepatitis C virus replication by cyclosporin $\mathrm{A}$ is mediated by blockade of cyclophilins. Gastroenterology 2005;129:1031-41.

18. Martin P, Busuttil RW, Goldstein RM, et al. Impact of tacrolimus vs. cyclosporine in hepatitis $\mathrm{C}$ virus-infected liver transplant recipients on recurrent hepatitis $\mathrm{C}$ : A prospective randomized trial. Liver Transpl 2004;10:1258-62.

19. Berenguer M, Crippin J, Gish R, et al. A model to predict severe $\mathrm{HCV}$-related disease following liver transplantation. Hepatology 2003;38:34-41.

20. Gedaly R, Clifford TM, McHugh PP, Jeon H, Johnston TD, Ranjan D. Prevalent immunosuppressive strategies in liver transplantation for hepatitis C: Results of a multi-center international survey. Transpl Int 2008;21:867-72.

21. Trotter JF. Sirolimus in liver transplantation. Transplant Proc 2003;35(Suppl 3):193S-200S.

22. Toso C, Meeberg GA, Bigam DL, et al. De novo sirolimus-based immunosuppression after liver transplantation for hepatocellular carcinoma: Long-term outcomes and side effects. Transplantation 2007;83:1162-8.

23. Kneteman NM, Oberholzer J, Al Saghier M, et al. Sirolimus-based immunosuppression for liver transplantation in the presence of extended criteria for hepatocellular carcinoma. Liver Transpl 2004;10:1301-11.

24. Toso C, Merani S, Bigam DL, Shapiro AM, Kneteman NM. Sirolimus-based immunosuppression is associated with increased survival after liver transplantation for hepatocellular carcinoma. Hepatology 2010;51:1237-43.

25. Neef M, Ledermann M, Saegesser H, Schneider V, Reichen J. Low-dose oral rapamycin treatment reduces fibrogenesis, improves liver function, and prolongs survival in rats with established liver cirrhosis. J Hepatol 2006;45:786-96.

26. Heuer M, Benkö T, Cicinnati VR, et al. Effect of low-dose rapamycin on tumor growth in two human hepatocellular cancer cell lines. Transplant Proc 2009;41:359-65.

27. Pelletier SJ, Schaubel DE, Wei G, et al. Effect of body mass index on the survival benefit of liver transplantation. Liver Transpl 2007;13:1678-83.

28. Lietz K, John R, Burke EA, et al. Pretransplant cachexia and morbid obesity are predictors of increased mortality after heart transplantation. Transplantation 2001;72:277-83.

29. Berenguer M, Aguilera V, Martín Prieto, et al. Effect of calcineurin inhibitors on survival and histologic disease severity in HCV-infected liver transplant recipients. Liver Transpl 2006;12:762-7. 


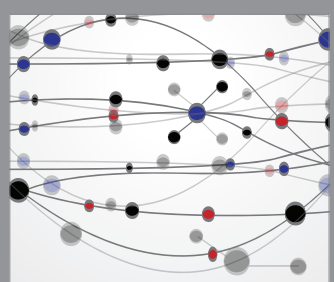

The Scientific World Journal
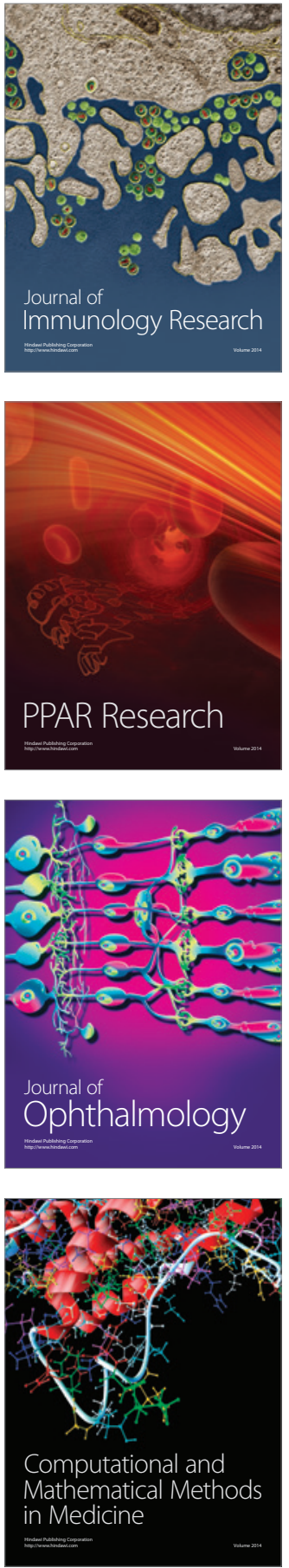

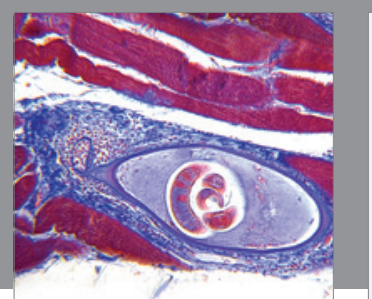

Gastroenterology Research and Practice

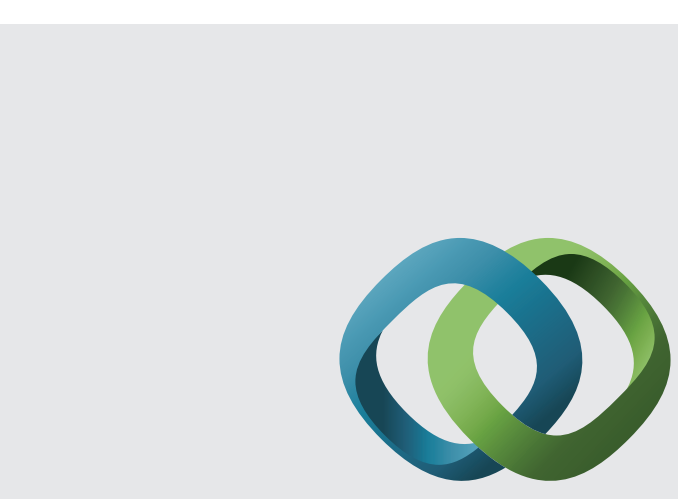

\section{Hindawi}

Submit your manuscripts at

http://www.hindawi.com
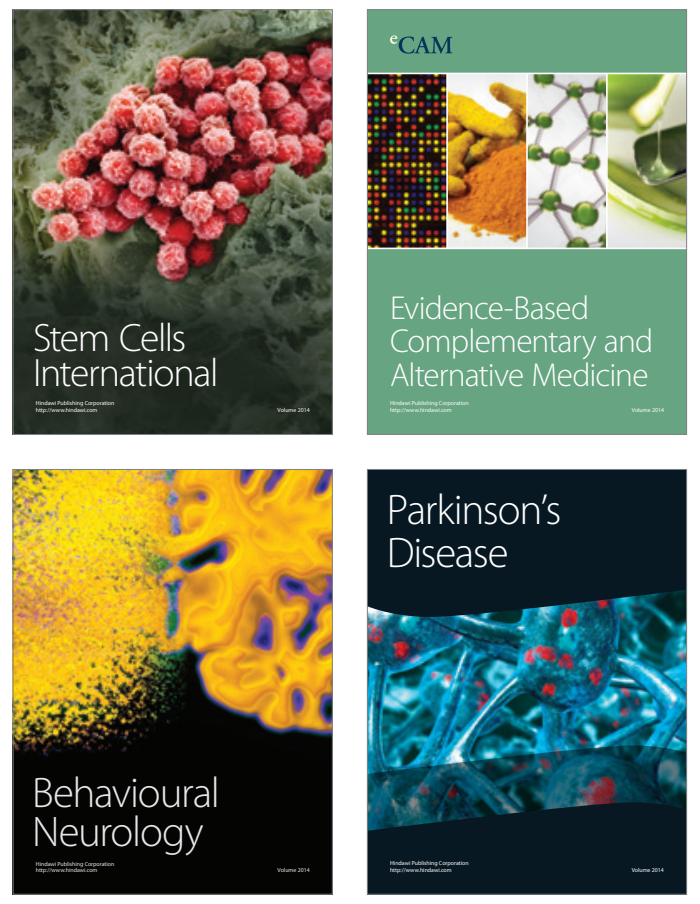
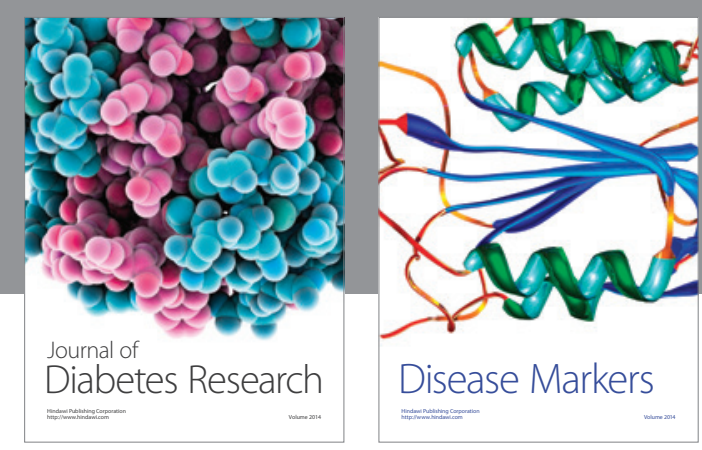

Disease Markers
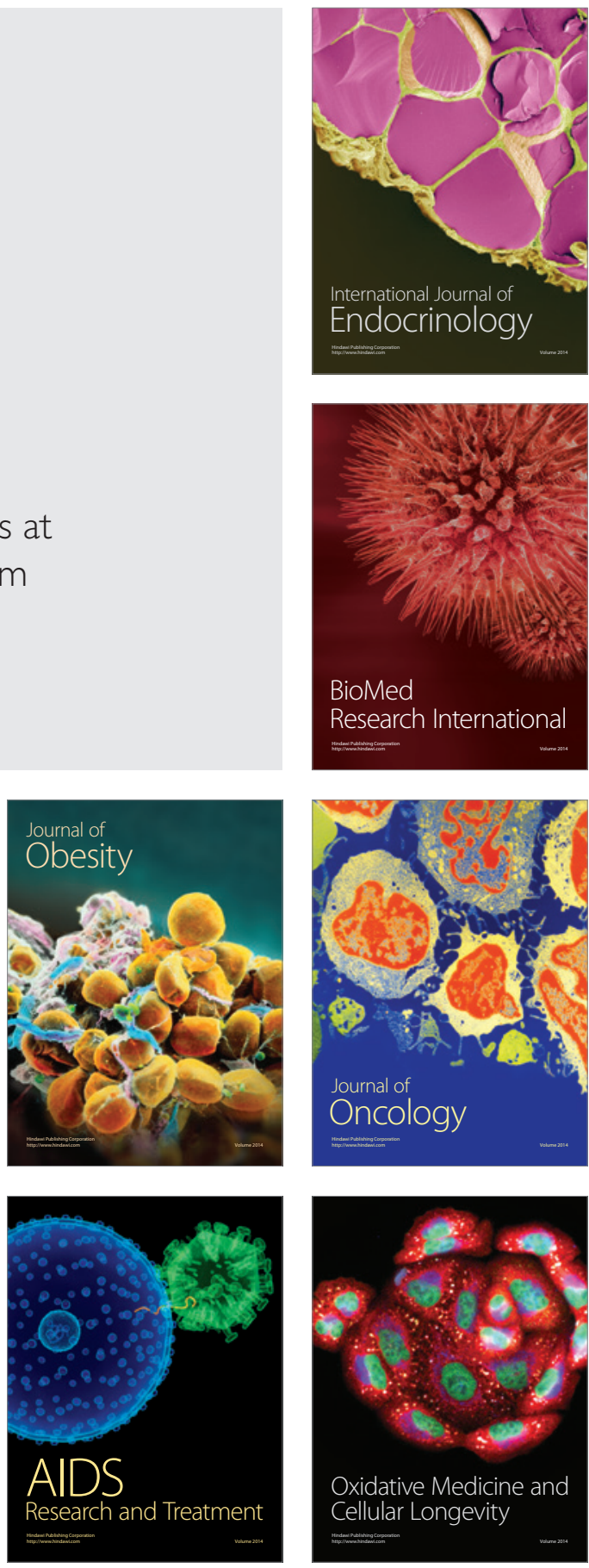